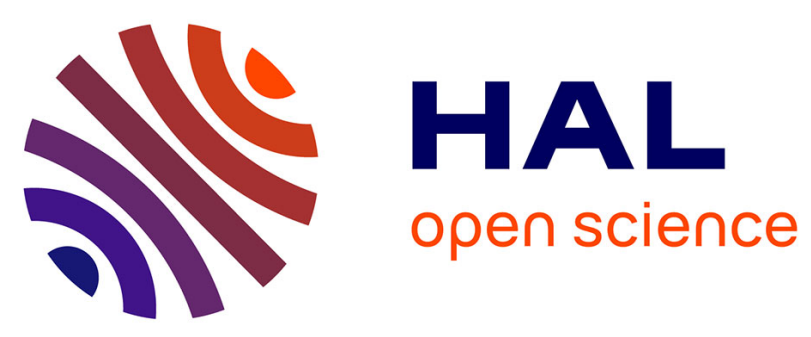

\title{
POM Mechanical Properties
}

\author{
Fahmi Bedoui, Bruno Fayolle
}

\section{To cite this version:}

Fahmi Bedoui, Bruno Fayolle. POM Mechanical Properties. Sigrid Lüftl, Visakh P.M., Sarath Chandran. Polyoxymethylene Handbook: Structure, Properties, Applications and their Nanocomposites (Polymer Science and Plastics Engineering), Wiley; Scrivener, pp.241-255, 2014, 978-1-118-38511-1. 10.1002/9781118914458.ch9 . hal-02798595

\section{HAL Id: hal-02798595 https://hal.science/hal-02798595}

Submitted on 5 Jun 2020

HAL is a multi-disciplinary open access archive for the deposit and dissemination of scientific research documents, whether they are published or not. The documents may come from teaching and research institutions in France or abroad, or from public or private research centers.
L'archive ouverte pluridisciplinaire HAL, est destinée au dépôt et à la diffusion de documents scientifiques de niveau recherche, publiés ou non, émanant des établissements d'enseignement et de recherche français ou étrangers, des laboratoires publics ou privés. 


\title{
POM mechanical properties
}

\author{
Fahmi Bedoui ${ }^{1}$ and Bruno Fayolle ${ }^{2}$
}

${ }^{1}$ Laboratoire Roberval, UMR-CNRS 7337, Université de Technologie de Compiègne, 1 rue Personne De Roberval, 60200 Compiègne.

2PIMM Arts et Metiers ParisTech, 151 Bd de l'Hopital , 75013 Paris, France

Thanks to its high degree of crystallinity, polyoxymethylene homopolymer exhibits high mechanical properties as strength, stiffness and creep. In the case of POM copolymer, the strength and stiffness are slightly lower because its lower crystallinity degree. Furthermore, the use domain is ranged from $-30^{\circ} \mathrm{C}$ to $150^{\circ} \mathrm{C}$ that allows various applications. More specifically to the POM, friction properties are excellent due to oxygen contained into the POM monomer.

The major drawback of POM homopolymer is its brittleness at RT compare to polyolefins, typically nominal strain at break values are close to $20 \%$. To improve mechanical properties at failure, different strategies can be adopted as POM copolymer have lower crystallinity degree (strain at break close 70\%) or added polyurethane in POM matrix (100ST from Dupont for instance). However, we will see that these strategies lead to material's stiffness decrease. At last, another possible way is the use specific processing conditions to induce oriented morphology. We will review all these aspects.

This chapter is divided in two major parts: the first part is devoted to short term mechanical properties as elastic properties as a function of temperature and morphology aspects, failure properties and the different strategies to improve them. The second part aims to present long term properties as creep behavior and modifications induced by ageing leading to an embrittlement of the POM limiting its lifetime.

\subsection{Short term properties}

\subsubsection{Elastic properties}

a) Modulus

Polyoxymethylene homopolymer tensile modulus (POM) is close to $3 \mathrm{GPa}$ at RT. However, since modulus value is crystallinity degree driven parameter by and as the latter can be different through sample thickness, this value of $3 \mathrm{GPa}$ could be considered an average. Indeed, typical processing conditions for thick sample lead to crystalline ration gradient. For instance, by using a specific device, Rémond et al. put in evidence that modulus varied from 2 GPa to a maximum of $3.2 \mathrm{GPa}$ for a depth of $0.5 \mathrm{~mm}^{1}$. As a result, POM mechanical properties have to be investigated for a given crystallinity 
ratio knowing the latter vary from 60 to $90 \%$. In order to assess the impact of the crystallinity on modulus, thin samples have to be used to ensure homogenous crystallinity through the thickness.

b) Modulus as a function of temperature

To illustrate influence of temperature on modulus values, we report at the Figure 1 the conservative modulus and $\tan (\delta)$ as a function of temperature using dynamical mechanical analysis (DMA) at $1 \mathrm{~Hz}$ in tensile mode, temperature ranging from $-120^{\circ} \mathrm{C}$ to $100^{\circ} \mathrm{C}$. POM homopolymer sample has $1 \mathrm{~mm}$ thickness, its crystallinity ratio is close to $63 \%$ and a melting temperature of $180^{\circ} \mathrm{C}$ (DSC).

First, glass transition can be observed from $-70^{\circ} \mathrm{C}$ to $-20^{\circ} \mathrm{C}$, typical value can be assessed by using the maximum of the $\tan (\delta)$ curve: $\operatorname{Tg} \sim-50^{\circ} \mathrm{C}$. During the transition, modulus drops from $8 \mathrm{GPa}$ where amorphous phase is in glassy state to $3 \mathrm{GPa}$ at $-20^{\circ} \mathrm{C}$ where amorphous phase is in rubber-like state. In the $-20^{\circ} \mathrm{C}$ to $60^{\circ} \mathrm{C}$ range, the modulus decreases slightly with temperature to reach a value close 2 GPa. After $70^{\circ} \mathrm{C}$, it is observed a transition often called Tac associated to the activation of crystalline phase mobility ${ }^{2}$. This transition is maximum to $140^{\circ} \mathrm{C}$ range leading to decrease the modulus down to $1 \mathrm{GPa}^{3}$. Of course, when temperature reaches $170^{\circ} \mathrm{C}$, i.e.

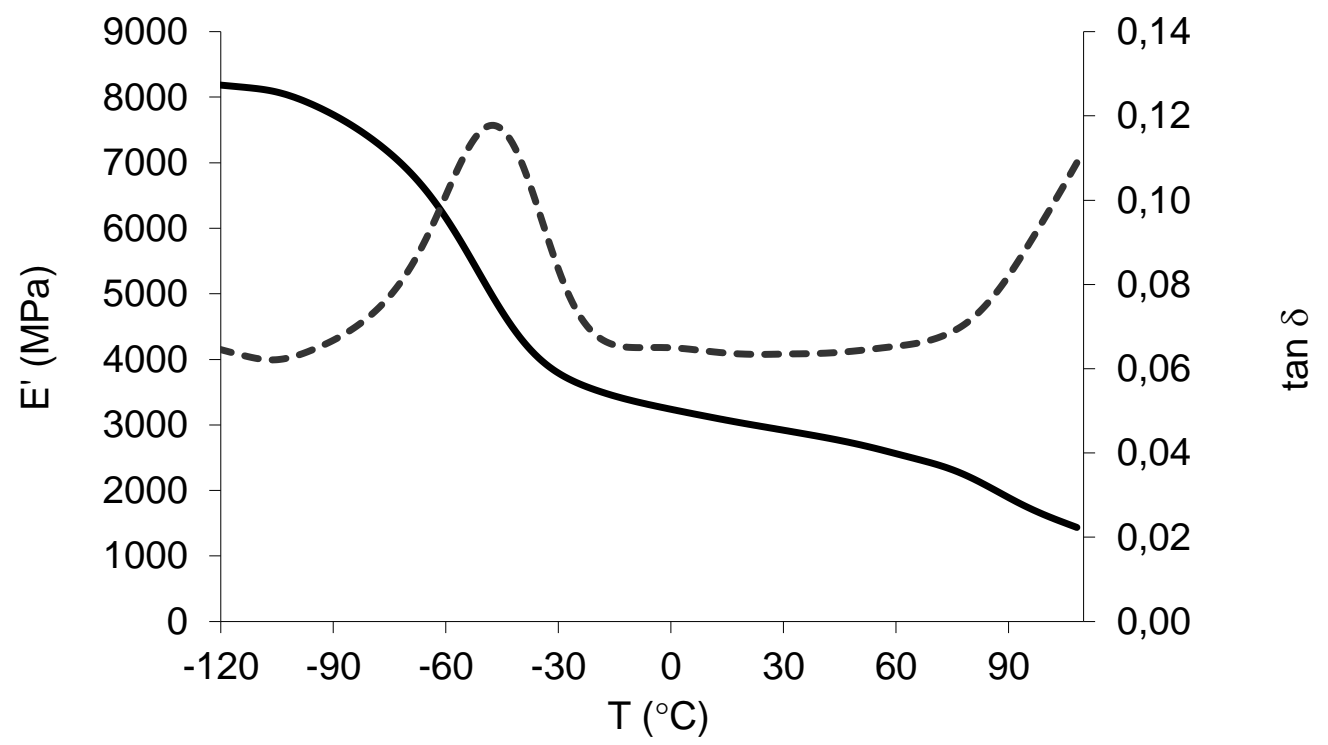

Figure 1: Conservative modulus ( $\left.E^{\prime}\right)$ and tan $\delta$ as a function of temperature (1 Hz).

c) Modulus as a function of crystallinity ratio

\section{POM Microstructure}

At a microscopic scale, semi-crystalline polymers, like POM, are heterogeneous materials consisting of co-existing amorphous and crystalline phases. The crystalline phase consists mainly of crystal 
lamellae. In a relaxed polymer melt, the principal crystal lamellae grow radially from nucleation sites into a spherulitic texture. Permanganate-based etching solutions ${ }^{4}$ help revealing the lamellar structure by increasing the amorphous-crystalline lamellae contrast (figure 2).

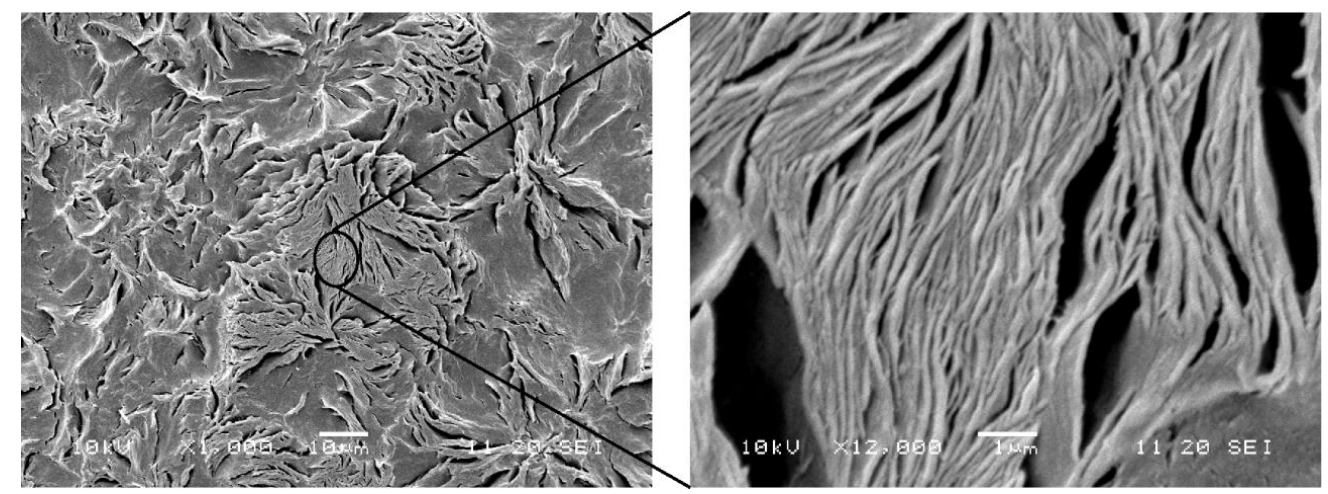

Figure 2: POM spherulitic and lamellar structure on chemically etched POM sample.

The lamellae are generally not isolated entities, but joined together by branch-points. Moreover, the stress in the polymer is transmitted between the two phases through tie-molecules and that content of tie-molecules depends on crystallization conditions. Crystallite lamellae could considered as embedded into the amorphous phase, assuming that crystalline branch-points are weak links therefore they do not play a role at low strain. Here, heterogeneities are considered at the subspherulitic scale and the two constitutive phases are the crystal lamellae and the amorphous phase. As such POM could be considered nano reinforced materials to whch micromechanical model could be applied.. Micromechanical modeling requires parameters such as phase behavior laws, volume fraction and morphology of each constitutive phase.

- Amorphous phase

As the glass transition temperature of the amorphous phase is lower than ambient temperature; therefore the amorphous phase is in the rubber-like state at ambient temperature. Chain entanglements are the cause of rubber-elastic properties in the liquid state theory of rubber elasticity developed by Flory ${ }^{5}$, leads to the following equation for the amorphous phase of thermoplastic polymers above the glass transition temperature

$$
G_{N}^{0}=\frac{\rho R T}{M_{e}}
$$

where $G_{N}^{0}$ is the shear modulus at plateau determined by rheological measurements, $\rho$ the amorphous phase density, $R$ the ideal gas constant, $T$ the temperature and $M_{e}$ the molecular mass between entanglements. The modulus at plateau $G_{N}^{0}$, is independent of chain length and not much sensitive to temperature. The molecular mass between entanglements $M_{e}$ is a material property, which can be considered temperature independent (Me $\sim 2.7 \mathrm{~kg} / \mathrm{mol}$ for POM 
homopolymer) ${ }^{6}$. Based on PVT data the Bulk modulus and the Poisson coefficient could be determined, for a given temperature, using the following equations:

$$
K=-\frac{1}{V} \frac{\partial V}{\partial P} \quad \text { and } \quad \vartheta=\frac{1}{2}\left(1-\frac{E}{3 * K}\right)
$$

where $\mathrm{E}$ stands for the rubber-like elastic modulus of the amorphous phase at room temperature $\left(E \approx 3 * G_{0}^{N}\right)$.

The following table presents a summary of the amorphous physical and mechanical properties ${ }^{6}$.

\begin{tabular}{lccccc}
\hline $\begin{array}{c}\text { Glass transition } \\
\text { temperature } \mathrm{T}_{\mathrm{g}}\end{array}$ & $\begin{array}{c}\text { Molar mass } \\
\text { between } \\
\text { entanglement }\end{array}$ & $\begin{array}{c}\text { Shear } \\
\text { modulus } \mathrm{G}^{0}\end{array}$ & $\begin{array}{c}\text { Bulk } \\
\text { modulus } \mathrm{K}\end{array}$ & $\begin{array}{c}\text { Elastic } \\
\text { modulus } \mathrm{E}\end{array}$ & Poisson Coefficient v \\
& $\mathrm{Me}$ & & & & \\
\hline-65 to $-30^{\circ} \mathrm{C}$ & $2.7 \mathrm{~kg} / \mathrm{Mol}$ & $1.3 \mathrm{MPa}$ & $4 \mathrm{GPa}$ & $3.9 \mathrm{MPa}$ & 0.499 \\
\hline
\end{tabular}

- Crystalline phase

The polymer crystal stiffness is related to the conformation of the molecular chain. Indeed the crystal lamellae are a result of chain folding. Along the chain axis, the covalently linked carbons induce higher modulus than in the other directions, where the stiffness is governed by the interchain interactions. Thus the crystalline lamellae is highly anisotropic with an elastic modulus in the chain direction is as high as $67 \mathrm{GPa}\left(E_{33}\right)$ compared to 14,67 and $18,01 \mathrm{GPa}$ in the other directions $\left(E_{11} \text { and } E_{22} \text { respectively }\right)^{7,8}$.

$$
\underline{\underline{\underline{\underline{C}}}}^{P O M}=\left(\begin{array}{cccccc}
19,2 & 6,3 & 16,9 & 0 & 0 & 0 \\
6,3 & 20,2 & 8,4 & 0 & 0 & 0 \\
16,9 & 8,4 & 83 & 0 & 0 & 0 \\
0 & 0 & 0 & 5,8 & 0 & 0 \\
0 & 0 & 0 & 0 & 5,6 & 0 \\
0 & 0 & 0 & 0 & 0 & 6,7
\end{array}\right) \text { GPa. }
$$

\section{Morphological representation and micromechanical modeling}

As described in the previous section, POM could be considered as heterogeneous materials made of two phases: crystalline lamellae and amorphous phase. . When it is isotropic, POM as a semicrystalline polymer could be represented either by an aggregate of layered two-phase composite 
inclusions which are randomly oriented or as an amorphous matrix in which crystalline lamellae act as a reinforcing inclusions ${ }^{9-11}$ (figure 3 ).

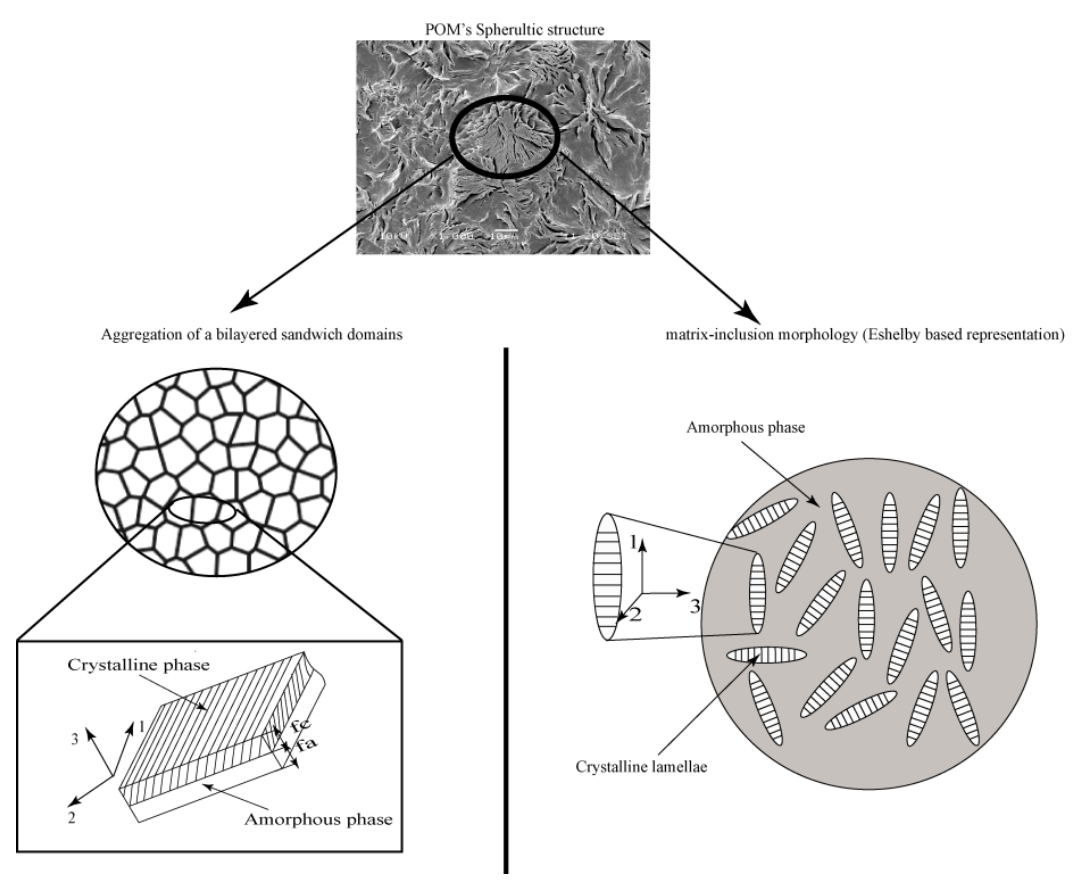

Figure 3: Spherulitic morphology and the possible micromechanical representation: aggregation of bilayered sandwich (right) or matrix inclusion representation (left).

The two representations were adopted to predict the elastic properties of semi-crystalline polymers ${ }^{9-}$ ${ }^{11}$. Different models were used such as differential scheme and hybrid models (Sigma-inclusion or Uinclusion $)^{9-11}$. In hybrid models only the crystalline fraction is needed as a morphological descriptor. Indeed, the crystalline lamellae with the neighboring amorphous phase are considered with infinite width and length. For differential scheme the shape ratio of the crystalline lamellae will be taken on account along with the crystalline fraction. In the figure 4, estimation of the Young's modulus using these previous cited models shows a better fit $f$ the experimental data using the differential scheme with crystalline lamellae shape ration determined based on the SEM pictures. 


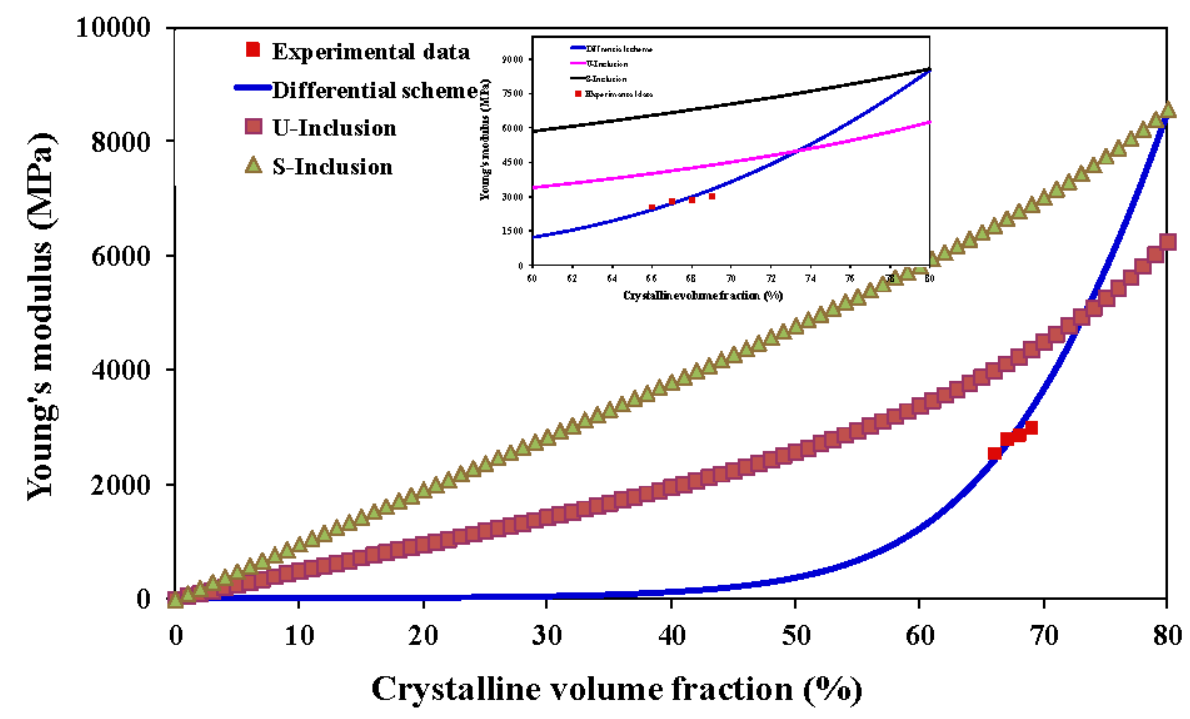

Figure 4: Young's modulus estimation using hybrid (Sigma-inclusion and U-inclusion) and differential scheme (shape ratio length/thickness = 28; width/thickness=8).

\subsubsection{Properties at failure}

From nominal stress-strain curve in tensile mode, plastic and failure properties are characterized by the yield stress $\left(\sigma_{y}\right)$ and the strain at break $\left(\varepsilon_{r}\right)$. Strain to break is a ductility descriptor, in other words plastic deformation and damage processes. The stress at break has to be used with caution since nominal stress is underestimated because of necking process. To characterize properly property at failure, the appropriate approach consists on using fracture mechanic concepts as $K_{\mathrm{I}}$ when plastic deformation is confined at the crack tip or essential work of fracture (EWF) method when plastic zone size is large compare to specimen geometry.

a) Mechanical behavior as a function of temperature

As elastic properties, mechanical behavior at large deformation and at failure is strongly temperature dependent . We report at the Figure 5, stress strain curves for a POM homopolymer ( $1 \mathrm{~mm}$ thick, Xc $\sim 63 \%$ ) at temperatures ranging from $20^{\circ} \mathrm{C}$ to $100^{\circ} \mathrm{C}$. If the stress at yield decreases with temperature increase, it is noteworthy that ductility is promoted by higher temperatures: if strain at break is close to $6 \%$ at $20^{\circ} \mathrm{C}$, it reaches more than $150 \%$ at $100^{\circ} \mathrm{C}$ 


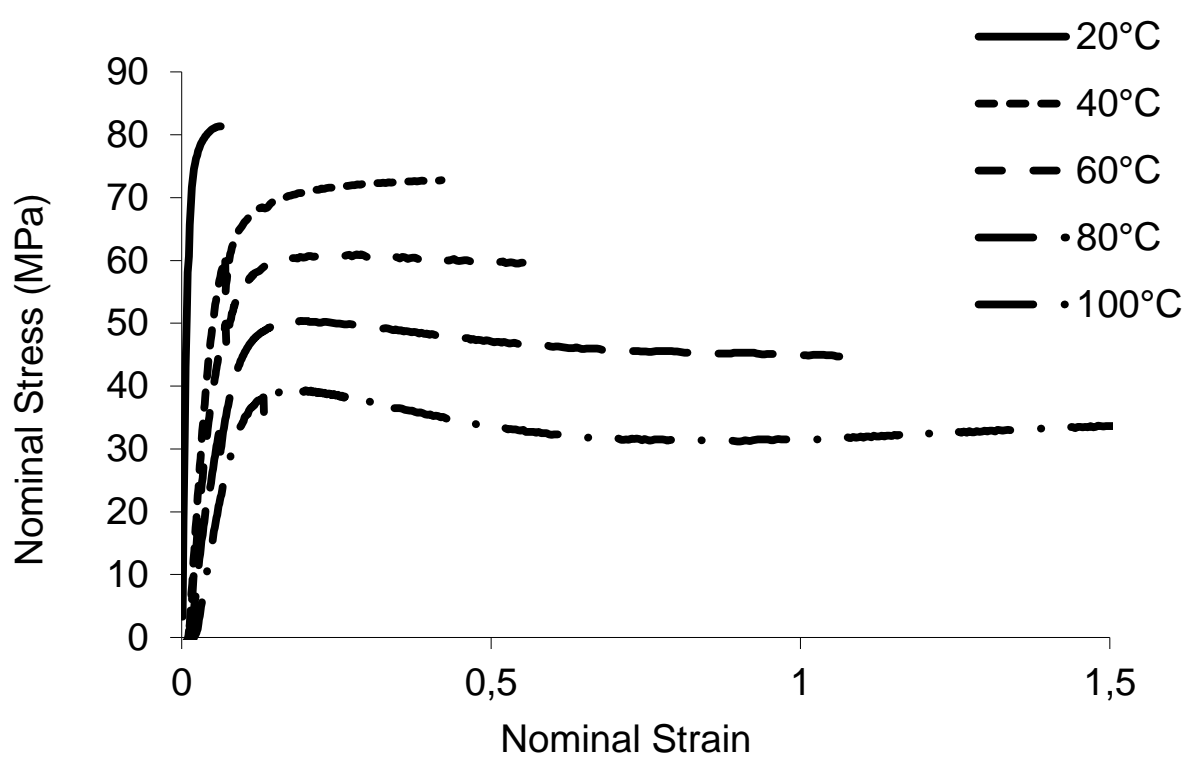

Figure 5: Nominal stress strain curves at different temperatures for Delrin $100{ }^{\circledR}$ POM homoplymer $\left(50 \mathrm{~mm} / \mathrm{min}\right.$ at $\left.20^{\circ} \mathrm{C}\right)$.

b) Fracture properties

As for the modulus, fracture properties depend not only on crystallinity but also on molar mass. Since POM is brittle at room temperature, linear fracture mechanic can be applied to assess fracture properties. For instance Plummer et al. ${ }^{12}$ performed mechanical test in Mode I opening of notched compact test specimens to determine $\mathrm{K}_{\mathrm{IC}}$. Typically if POM samples are crystallized below a crystallization temperature of $140^{\circ} \mathrm{C}, \mathrm{K}_{\mathrm{IC}}$ is ranging between 4.4 to $5 \mathrm{MPa} \mathrm{m} \mathrm{m}^{1 / 2}$ depending on the sample's molar molar mass $\left(35<\mathrm{M}_{\mathrm{n}}<66 \mathrm{~kg} \text {. mol}{ }^{-1}\right)^{13}$. Indeed, for this crystallization conditions $\mathrm{K}_{\mathrm{Ic}}$ is a molar mass driven property. However, for very low crystallization rate conditions, they observe a decrease of $\mathrm{K}_{\mathrm{IC}}$ that indicates the crystalline morphology can play a role in fracture mechanisms responsible for fracture properties.

At high temperatures, typically $100^{\circ} \mathrm{C}$, we have seen previously that $\mathrm{POM}$ is highly ductile, hence the linear fracture mechanic cannot be applied to assess fracture properties. The most appropriate mechanical test is then Essential Work of Fracture test. Indeed, this test take onto account energy dissipated into the large plastic zone in notched specimen ${ }^{14}$. In this test, the essential work of fracture $\left(w_{e}\right)$, corresponding to energy required for the creation of unit area of crack face, is considered to be a materials parameter in the case of thin specimens. If $w_{e}$ is slightly dependent of test speed, $w_{e}$ increases with molar mass: from $6 \mathrm{~kJ} / \mathrm{m}^{2}$ for $M_{n}=33 \mathrm{~kg} / \mathrm{mol}$ up to $14 \mathrm{~kJ} / \mathrm{m}^{2}$ for $M_{n}=66$ $\mathrm{kg} / \mathrm{mol}^{12}$.

As a conclusion, POM fracture properties are strongly dependent on molar mass whatever the POM mechanical tests are carried out at room temperature in its brittle regime or at high temperature 
(typically $100^{\circ} \mathrm{C}$ ) in its ductile regime. This dependence can be explained by entanglements density and/or tie molecule density increase with the molar mass.

c) How to improve POM mechanical properties?

- Processing-induced orientation

As in polyethylene fibers, chain orientation leads to improve significantly mechanical properties as fracture properties. This route has been explored for POM by many research groups, especially Ward et al. ${ }^{15-17}$. Solid-state orientation processes can be performed by using tensile free drawing, diedrawing, hydrostatic extrusion, rolling, roll-drawing, constrained rolling process and equal channel extrusion process. For instance, the modulus increases from $3.5 \mathrm{GPa}$ to $15 \mathrm{GPa}$ and the tensile strength from $90 \mathrm{MPa}$ to $700 \mathrm{MPa}$ linearly with draw ratio ${ }^{18}$. By these ways, not only modulus can be improved but also strength or creep properties ${ }^{19}$. These improvements are often attributed to specific loading fields that inhibit the cavitation process (main damage phenomenon)mechanisms occurring during plastic deformation ${ }^{15,20,21}$.

- POM blends

As we have seen previously, POM homopolymer is brittle in notched impact. Cherdon, et al. ${ }^{22}$ proposed to improve impact properties by blending POM with various polymers. For instance Wurmb, et al. ${ }^{23} \mathrm{Chiang}$, et al. ${ }^{24}$ suggested adding thermoplastic polyurethane (TPU) to enhance the impact properties of POM and glass fiber reinforced POM .Other researchers assessed the consequences of rubber particles or elastomeric graft copolymer on impact properties ${ }^{25}$. At last, Flexman put in evidence that a series POM/TPU compositions exhibit high impact properties ${ }^{26}$. However we will notice that the literature about the consequence of POM toughening on impact properties is scarce since the studies are often linked to patents.

To illustrate the consequence of elastomer PU, we report in Figure 6 nominal stress-strain curves for Delrin $100^{\circledR}$ and $\mathrm{POM} /$ polyurethane Delrin $100 \mathrm{ST}^{\circledR}$. If strain at break increases significantly by adding PU (from 7\% for POM homopolymer to 35\% for POM/PU), we can witness however the modulus and the yield stress as defined before are lower for POM/PU. 


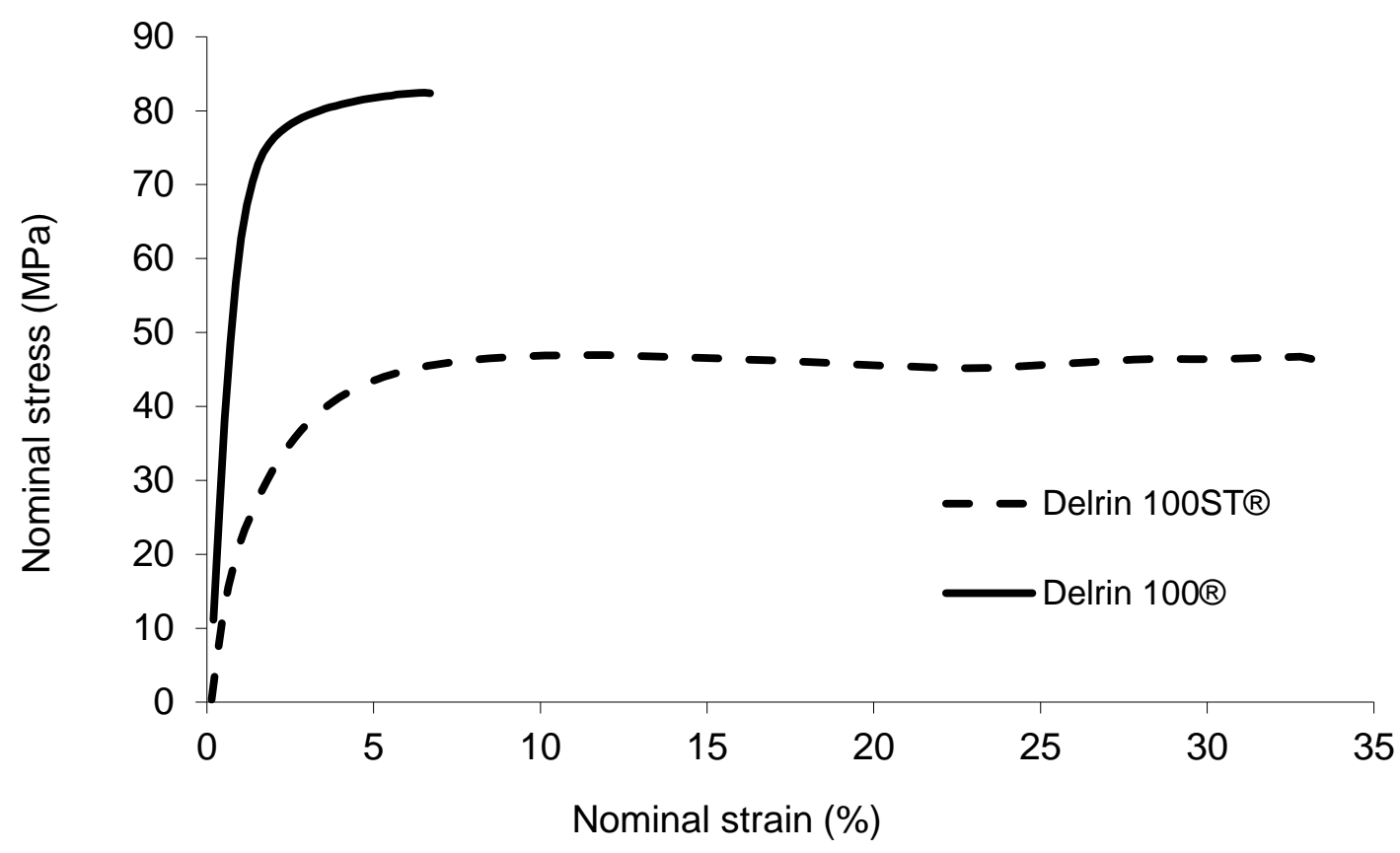

Figure 6: Nominal stress-strain curves for Delrin $100^{\circledast}$ and Delrin $100 S T^{\circledast}\left(50 \mathrm{~mm} / \mathrm{min}\right.$ at $\left.20^{\circ} \mathrm{C}\right)$.

\subsection{Long term properties}

\subsubsection{Fatigue properties}

Although the POM shows a brittle behavior at room temperature, some authors have highlighted that the POM is the most fatigue resistant engineering plastic among available semicristalline polymers ${ }^{27}$. However, as for the previous mechanical properties, molar mass and crystalline morphology have a strong influence on fatigue crack propagation in POM. Fatigue properties are worked out by plotting crack growth rate $(\mathrm{da} / \mathrm{dn})$ as a function of stress intensity factor range $(\Delta K)$ as it is defined in ASTM standard E399-83. The $\log (\mathrm{da} / \mathrm{dn})-\log (\Delta \mathrm{K})$ curve exhibits usually a sigmoidal shape in which the second region is associated to a stable crack propagation. Thanks to this linear region, the $A$ and $m$ parameters of the Paris law $d a / d n=A \Delta K^{m}$ can be determined. Some log $(d a / d n)-$ $\log (\Delta K)$ curves are available in literature ${ }^{28}$. For instance, Runt et al. studies put in evidence improvements in fatigue crack resistance with molar mass. This result has been attributed to enhanced tie molecule density by these authors ${ }^{29}$. Moreover, POM/PU fatigue properties has been studied: the authors indicated a strong influence of a core-skin morphology (spherulite morphology, rubber rode dispersion) ${ }^{30}$. At last, some authors showed that fatigue properties of POM are also dependant on the stabilizer agent concentration as chemical degradation by oxidation could occur during test ${ }^{31}$ : they have shown that the A parameter of the Paris law is strongly depend on stabilizer 
concentration. As a result, oxidation process can affect POM lifetime in fatigue since the oxidation promotes a chain scission process as we will focus on below.

\subsubsection{Chemical degradation}

Polymers long terms properties are often governed by chemical degradations occurring during service conditions. Indeed, the chemical degradation promotes chain scission or crosslinking processes leading to polymers embrittlement. In the case of POM, the main mechanism responsible of embrittlement during its use is the oxidation phenomenon. That is the reason why the POM is stabilized by adding antioxidants (see Chapter Richaud). According to several studies about POM oxidation in air, the chain scission process is predominant over the crosslinking one ${ }^{32}$. As a result of the chain scission, molar mass decrease leads to embrittlement during exposure ${ }^{33}$. A similar mechanism can be obtained when POM is $\gamma$-irradiated. Indeed POM radiolysis leads to the chain scission process because its monomer-monomer bonds show low dissociation energy as PMMA and the mechanism could be the following:

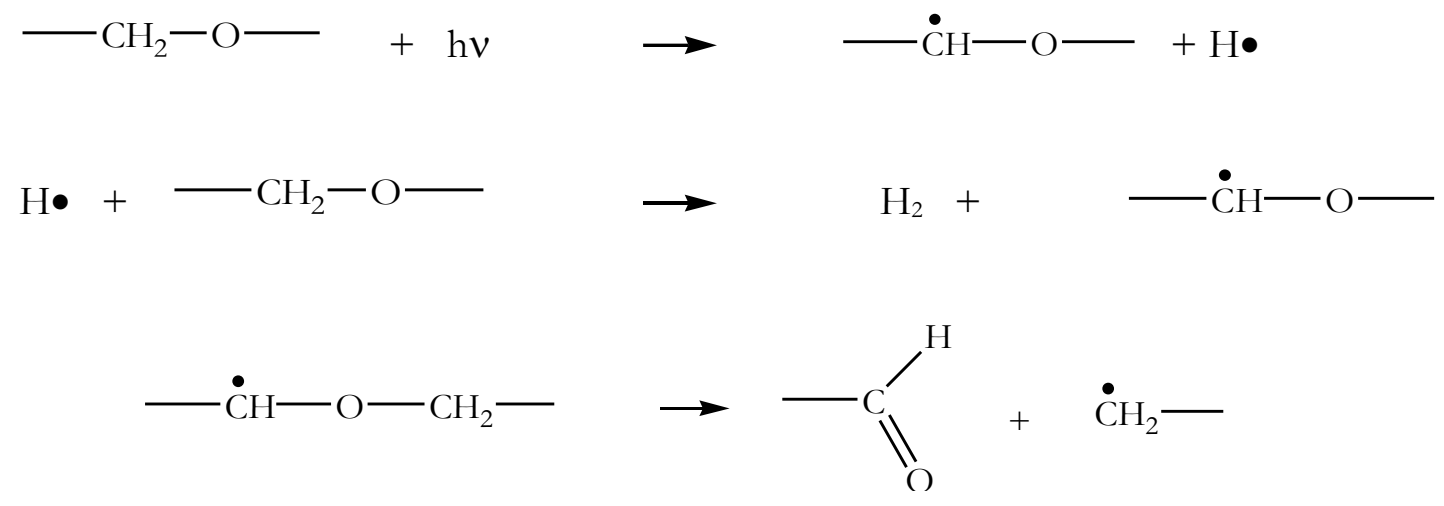

Since the molar mass decreases during chemical degradation by chain scission (oxidation or radiolysis), modifications of POM crystalline morphology can be observed ${ }^{34}$. The first major change is a degree of crystallinity increase due to a chimicrystallization process. Indeed, the molar mass reduction leads to promote amorphous chains mobility. These new segments can then integrate crystalline lamellae. In Figure 7-a, degree of crystallinity values are correlated with number of chain scission, these changes has been obtained during a radiolysis process. This correlation helped put in evidence chemically-induced crystallization phenomenon during degradation. Since this increase of crystallinity can be attributed to an integration of chains from the amorphous phase to the crystalline phase, one can expect that the increase of crystallinity is due to a crystallite thickening while the long period remainins constant. To confirm this scenario, amorphous layer assessment by small angle $\mathrm{X}$ ray scattering technique (SAXS) is then required. Amorphous layer thickness values as a function of 
molar mass square root during degradation are reported in Figure 7-b showing a good correlation between embrittelement and amorphous layer thickness.. As a result, we can conclude that if POM is submitted to a chemical degradation leading to a chain scission process, molar mass values decreases and crystallinity increases. Both aspects have to take into account to understand the POM ductilebrittle transition during the chemical degradation.
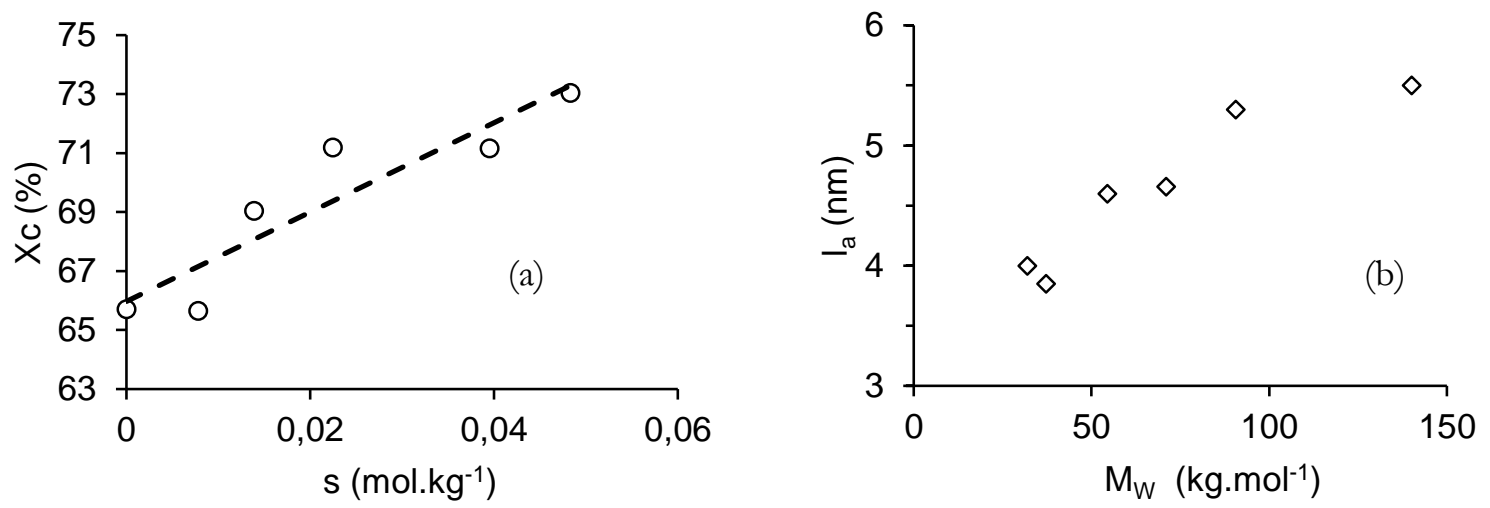

Figure 7: (a) Degree of crystallinity $\left(X_{C}\right)$ as a function of chain scission number (s), (b) amorphous layer thickness $\left(I_{a}\right)$ as a function of weight average molar mass $\left(M_{w}\right)$ during degradation.

To correlate the molar mass and crystallinity changes and the embrittlement process, tensile curves are reported in Figure 8 for each degradation states (different molar mass $\left(M_{w}\right)$ ). Tensile tests are performed at $100^{\circ} \mathrm{C}$ to put in evidence ductility. Before degradation, i.e. for molar mass equal to 140 kg.mol- ${ }^{-1}$, the mechanical behavior is strongly ductile up to $130 \%$. For a chain scission number close to 0.014 mol. $\mathrm{kg}^{-1}$ corresponding to $\mathrm{M}_{\mathrm{w}}=71 \mathrm{~kg} / \mathrm{mol}$, strain at break value remains constant at $130 \%$. However, strain at break values drop for molar mass values lower than $55 \mathrm{~kg} \mathrm{~mol}^{-1}$, to reach values close to $10 \%$ corresponding to the initial values for strain at yield. It's noteworthy that the degradation by chain scission does not affect significantly stress at yield values whereas the degradation leads to limit the plastic deformation. 


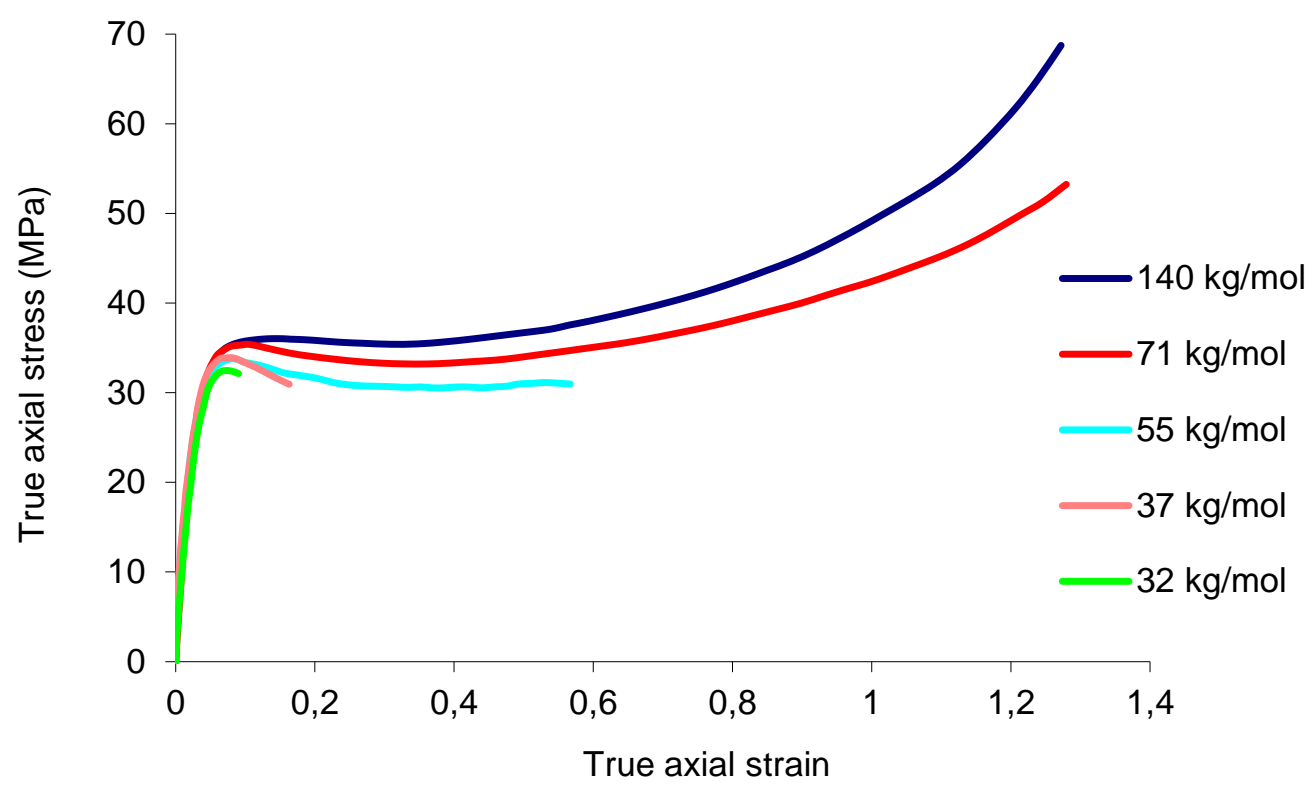

Figure 8 : Stress strain curves of POM during chain scission degradation at $100^{\circ} \mathrm{C}$ and $10^{-3} \mathrm{~s}^{-1}$.

In order to establish a link between molar mass, crystalline morphology and failure properties changes during degradation, we propose to summarize experimental data in a map where the amorphous layer thickness is plotted as a function of the molar mass (See Figure 9). POM is highly ductile if the molar mass is higher than $70 \mathrm{~kg} \cdot \mathrm{mol}^{-1}$ and $5 \mathrm{~nm}$ for the amorphous layer value. The ductile-brittle transition occurs between 40 and $70 \mathrm{~kg} \cdot \mathrm{mol}^{-1}$ and 4 and $5 \mathrm{~nm}$ for the molar mass and for the amorphous layer thickness, respectively. Below these values, strain at break values are lower than $0.2(20 \%)$, in other words POM is brittle.

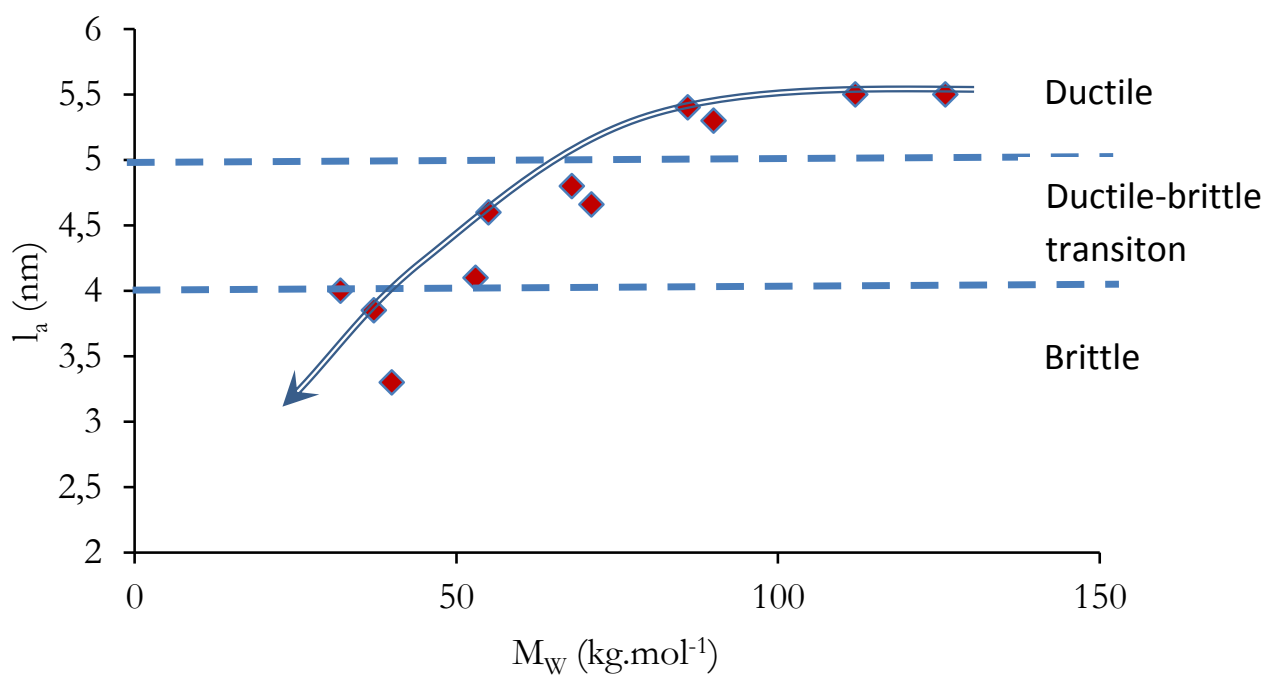


Figure 9 : amorphous layer thickness as a function of molecular weight $\left(\mathrm{I}_{\mathrm{a}}-\mathrm{M}_{\mathrm{w}}\right)$ and mechanical behavior (ductile, ductile brittle transition and brittle region).

\section{Conclusion}

The poly(oxy methylene) could be considered as high performance polymer due to its high mechanical properties. At short term use, it presents a high elastic properties as a result of the high crystalline fraction. Indded, despite the fact that the amorphous phase is in rubber-like state at room temperature, POM still have an elastic modlus af about 3 to $4 \mathrm{GPa}$. Indeed the elastic modulus of POM crystalline phase made of stiff crystalline lamellae organized either in spherulitic or oriented morphology will more than compensate for the weak amorphous phase. However, at room temperature, POM shows highly brittle behavior, which could be enhanced by using rubber reinforcing particles such as thermo plastic poly(urethane) or rubber particles.

For longterm use, POM major drawback is aging-induced embrittelement. Indeed POM oxidation or radiolysis lead to chain scission. As a consequence of chain scission, a molar mass decrease occur which in turn decreases the POM performances in static or dynamic loading. The use of antioxydation agent as an inhibitor of chain scission is the most common solution (see Richaud Chapter).

Acknowledgement: The authors acknowledge the precious help from Dr. Abdessalam Dahoun, Julie Diani, Gilles régnier and Andrew Galeski for their help in performing the tensile tests, micromechanical simulation and morphological study on POM. 
References

1. Rémond, Y.; Védrines, M., Polymer Testing 23, 2672004.

2. Rault, J., C37 (2) 335, 335.

3. Johnson, M. in Chemical Engineering; Virginia Polytechnic Institute and State University, Blakcsburg-Virginia: 2000.

4. Shahin, M. M.; Olley, R. H., Journal of Polymer Science Part B: Polymer Physics 40, 1242002.

5. Flory, P. J., Principles of Polymer Chemistry; Cornell University Press (Ithaca NY), , 1953.

6. Bédoui, F.; ENSAM-PARIS, Paris: 2005.

7. Tashiro, K., Progress in Polymer Science 18, 3771993.

8. Tashiro, K.; Kobayashi, M., Polymer 37, 17751996.

9. Bédoui, F.; Diani, J.; Régnier, G., Polymer 45, 24332004.

10. Bédoui, F.; Diani, J.; Régnier, G.; Seiler, W., Acta Materialia 54, 15132006.

11. van Dommelen, J. A. W.; Parks, D. M.; Boyce, M. C.; Brekelmans, W. A. M.; Baaijens, F. P. T., Polymer 44, 60892003.

12. Plummer, C. J. G.; Scaramuzzino, P.; Kausch, H. H.; Steinberger, R.; Lang, R. W., Polymer Engineering \& Science 40, 9852000.

13. Plummer, C. J. G.; Kausch, H. H., Journal of Macromolecular Science, Part B 35, 6371996.

14. Saleemi, A. S.; Nairn, J. A., Polymer Engineering \& Science 30, 2111990.

15. Komatsu, T.; Enoki, S.; Aoshima, A., Polymer 32, 19831991.

16. Brew, B.; Ward, I. M., Polymer 19, 13381978.

17. Clark, E. S.; Scott, L. S., Polymer Engineering \& Science 14, 6821974.

18. Mohanraj, J.; Bonner, M. J.; Barton, D. C.; Ward, I. M., Polymer 47, 58972006.

19. Coates, P. D.; Ward, I. M., Journal of Polymer Science: Polymer Physics Edition 16, 20311978.

20. Taraiya, A. K.; Mirza, M. S.; Mohanraj, J.; Barton, D. C.; Ward, I. M., Journal of Applied Polymer Science 88, 12682003.

21. Takeuchi, Y.; Yamamoto, F.; Konaka, T.; Nakagawa, K., Journal of Polymer Science Part B:

Polymer Physics 24, 10671986.

22. Cherdon, H.; Burg, K., US: 1974.

23. Wurmb, R., US: 1974.

24. Chiang, W.-Y.; Lo, M.-S., Journal of Applied Polymer Science 36, 16851988.

25. Chang, F.-c.; Yang, M.-Y., Polymer Engineering \& Science 30, 5431990.

26. Flexman Jr, E., Mod. Plast 62, 721985. 
27. Hertzberg, R. W.; Skibo, M. D.; Manson, J. A., J Mater Sci 13, 10381978.

28. Lazzeri, A.; Marchetti, A.; Levita, G., Fatigue \& Fracture of Engineering Materials \& Structures 20, 12071997.

29. Runt, J.; Gallagher, K. P., J Mater Sci 26, 7921991.

30. Pecorini, T. J.; Hertzberg, R. W.; Manson, J. A., J Mater Sci 25, 33851990.

31. Showaib, E. A.; Wyzgoski, M. G., J Mater Sci 37, 18952002.

32. Fayolle, B.; Verdu, J.; Bastard, M.; Piccoz, D., Journal of Applied Polymer Science 107, 1783 2008.

33. Fayolle, B.; Verdu, J.; Piccoz, D.; Dahoun, A.; Hiver, J. M.; G'Sell, C., Journal of Applied Polymer Science 111, 4692009.

34. Fayolle, B.; Verdu, J., European Polymer Journal 47, 21452011. 